GEOLOGICAL SURVEY CIRCULAR 671
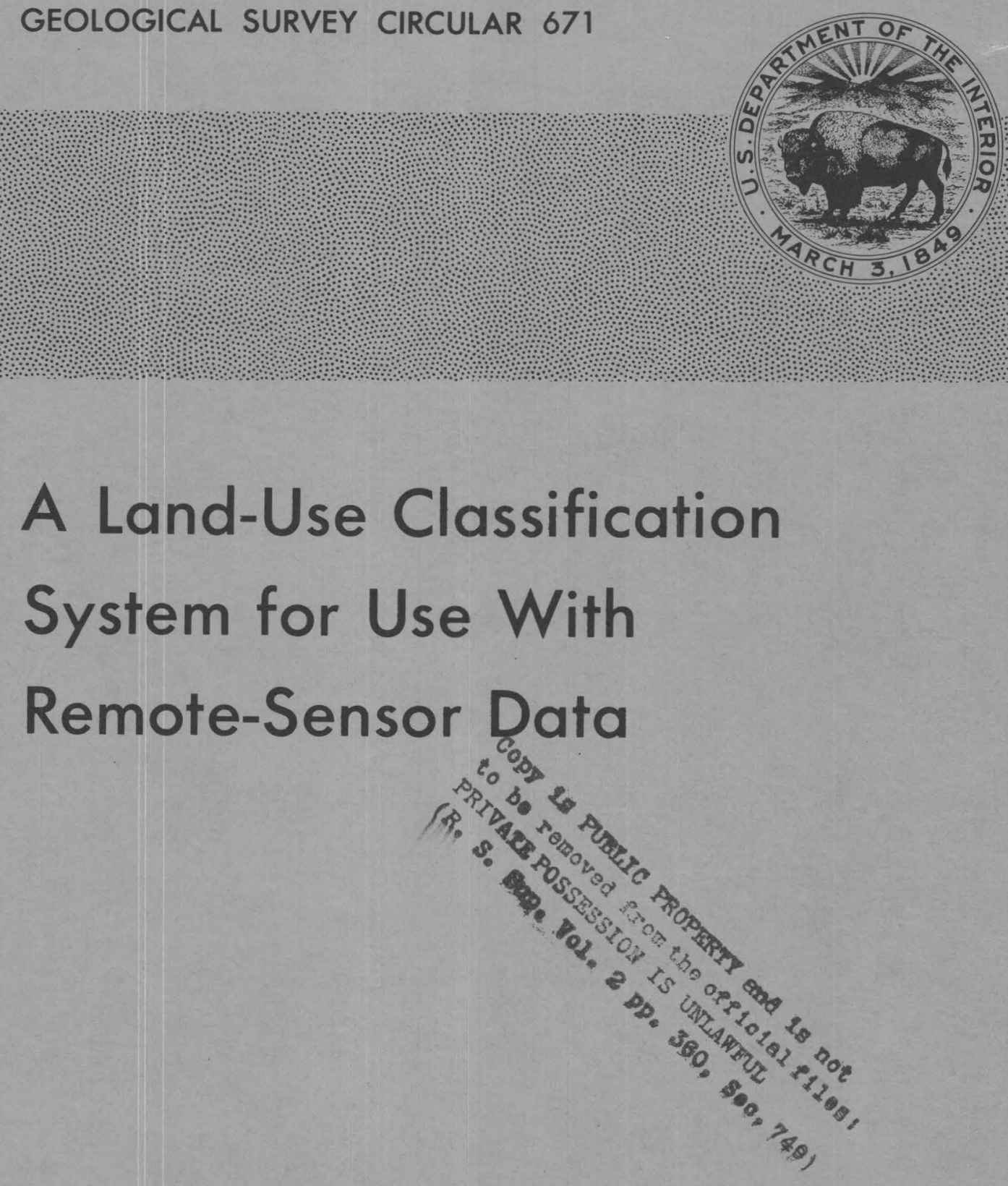



\section{A Land-Use Classification System for Use With Remote Sensor Data}

By James R. Anderson, Ernest E. Hardy, and John T. Roach

GEOLOGICAL SURVEY CIRCULAR 671

For the Inter-Agency Steering Committee on Land Use Information and Classification 
United States Department of the Interior ROGERS C. B. MORTON, Secretary

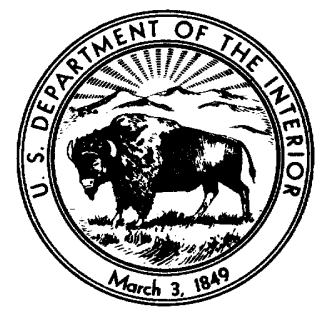

Geological Survey

V. E. McKelvey, Director 


\section{CONTENTS}

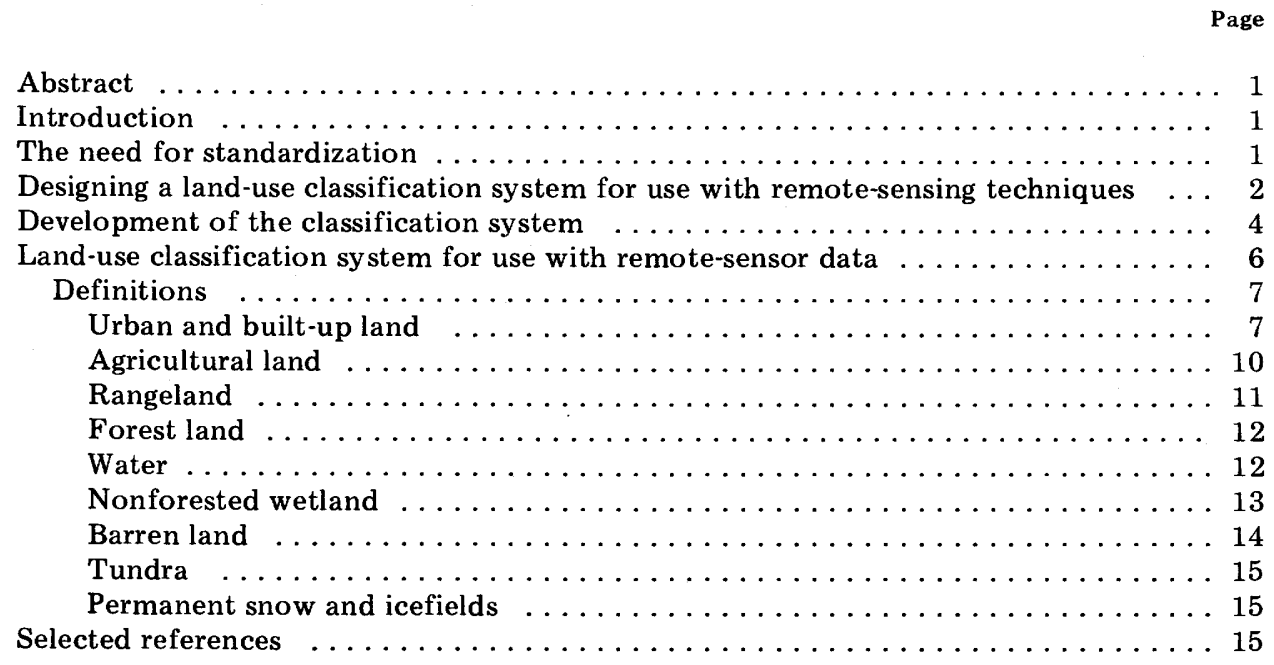




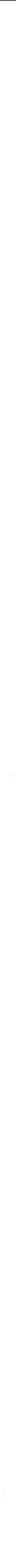




\title{
A Land-Use Classification System for Use With Remote-Sensor Data
}

\author{
By James R. Anderson, Ernest E. Hardy, and John T. Roach \\ for the \\ Inter-Agency Steering Committee on Land Use Information \\ and Classification
}

\begin{abstract}
The framework of a national land-use classification system is proposed for testing and review. The classification has been developed to meet the needs of Federal and State agencies for an up-to-date overview of land use throughout the country on a basis that is uniform in date, scale, and categorization at the more generalized first and second levels and that will be receptive to data from instrumented satellite and high-altitude aircraft platforms. The classification system utilizes the best features of existing widely used classification systems to the extent that they are amenable to use with remote-sensing, and it is open-ended so that regional, state, and local agencies may develop more detailed land-use classification systems, at third and fourth levels, to meet their particular needs and at the same time remain compatible with each other and with the national system.
\end{abstract}

\section{Introduction}

A modern nation, as a modern business, must have adequate information on many complexly interrelated aspects of its activities in order to make decisions. Land use is only one such aspect, but it is one that has become increasingly important as the nation seeks to grapple with the problems of slum clearance and urban renewal, and of suburban expansion, highway planning, and transportation systems. Land use can also serve as an effective surrogate in the analysis of environmental processes and problems that must be better understood if living conditions are to be enhanced.

\section{The Need for Standardization}

For many years, agencies at various governmental levels have been collecting data about land, but for the most part they have worked independently and without coordination. Too often this has meant duplication of effort, or it has been found that data collected for a specific purpose were of little or no value for a similar purpose only a short time later.

Remote-sensing techniques, including conventional aerial photography, can now be used effectively to complement surveys based on ground observation and enumeration, so we have the potential of a timely and accurate inventory of the current use of the nation's land resources. At the same time, data processing techniques permit the storage of large quantities of detailed information that can be organized in a variety of ways to meet specific needs.

As the result of long concern about duplication and coordination among Federal, State, and local governments in the collection and handling of different types of data, we have already in some instances achieved reasonably 
effective, though not perfect, solutions, as evidenced by present programs in soil surveys, topographic mapping, collection of weather information, and the inventory of forest resources. The recent developments in data-processing and remote-sensing technology make the need for similar cooperation in land-use inventories that much more evident and more pressing. Development and acceptance of a system for classifying land-use information, obtained primarily by use of remote-sensing techniques but reasonably compatible with existing classification systems, is the urgently needed first step.

\section{Designing a Land-Use Classification Sys- tem for Use With Remote-Sensing Techniques}

There is no ideal classification of land use, and it is unlikely that one will ever be developed. There are different perspectives in the classification process, and the process itself tends to be subjective even when an objective numerical approach is used. There is, in fact, no logical reason to expect that one detailed inventory will be adequate for more than a relatively short period of time. Land-use patterns change, as do our demands for the natural resources which affect the development of land-use patterns. Each land-use classification is made to suit the needs of the user, and few users will be satisfied with an inventory that does not meet most of their needs. In attempting to develop a classification system for use with remote-sensing techniques that will satisfy the needs of the majority of users, certain guidelines of criteria for evaluation must first be established.

To begin with, there is considerable diversity of opinion about what constitutes "land use," although present use of land is one of the characteristics that is widely recognized as significant for planning and management purposes. One concept that has much merit is that land use refers to "man's activities on land which are directly related to the land" (Clawson and Stewart, 1965). Land cover, on the other hand, would describe "the vegetational and artificial constructions covering the land surface" (Burley, 1961).

Some activities of man can be directly related to the type of land cover. The presence of planted corn most probably indicates that farming is the land-using activity on that particular tract. Thus, from imagery on which corn can be identified as the land cover, it may be reliably inferred that farming, which may not be actually visible, is the present activity. Other activities, especially recreational activities, can be related to land cover by use of remote-sensing techniques only with difficulty. Hunting is a common recreational use, but most hunting is done on land that is better classified as forest, range, or agricultural land, and complementary techniques will be needed to identify hunting as a land-using activity. Land cover is therefore the basis for categorization at the first and second levels, and the activity dimension of land use will appear at third and fourth levels of categorization.

In almost any classification process, it is rare to find the clearly defined classes that we would like. In determining land cover, it would seem simple to draw the line between land and water, until one considers the problems of seasonally wet areas, tidal flats, or marshes with various kinds of plant cover. Most types of land use appear in a continuous gradation from zero, or no use, to 100 , or full use. The problem to be solved is where to place the boundary around the use we wish to classify. How small an area of land with discarded equipment on it should be called a junkyard? How large an area should be in any particular use before we recognize the use? How do we resolve the problem of heterogeneous mixtures of equally significant land uses? Or of multiple uses of an area? Decisions that may seem arbitrary at times must be made, but if the descriptions of categories are complete and guidelines are explained, the inventory process can be repeated. The classification system must allow for the classification of all parts of the area under study and should also provide a unit of reference for each land use. 
A land-use classification system for use with orbital imagery should meet the following criteria (Anderson, 1971):

1. The minimum level of accuracy in the interpretation of the imagery should be about 90 percent.

2. The accuracy of interpretation for the several categories should be about equal.

3. Repeatable or repetitive results should be obtainable from one interpreter to another and from one time of sensing to another.

4. The classification system should be usable or adaptable for use over an extensive area.

5. The categorization should permit vegetation and other types of land cover to be used as surrogates for activity.

6. The classification system should be suitable for use with imagery taken at different times of the year.

7. Effective use of sub-categories that can be obtained from ground surveys or from the use of larger-scale or enhanced imagery should be possible.

8. Collapse of categories must be possible.

9. Comparison with land-use information compiled in the past or to be collected in the future should be possible.

10. Multiple-use aspects of land use should be recognized when possible.

It is hoped that in the use of this proposed land-use classification system, which involves only Levels I and II, an accuracy in interpretation can be attained that will make the land-use information comparable in quality to that obtained in other ways. For many users of land-use information, the accuracy of interpretation at the generalized first and second levels is satisfactory when the interpreter makes the correct interpretation 85 to 90 percent of the time. Greater accuracy will generally be attained only at much higher costs, which may not be justified for the purposes for which the information is obtained.

The accuracy ultimately attainable at each level of the classification system will in large part be determined by the capabilities of the sensors. At present, we are quite well apprised of the capabilities of aerial photographs at scales of
$1: 50,000$ to $1: 20,000$ or larger. We have limited experience with imagery at scales between $1: 50,000$ and $1: 120,000$ and essentially no experience to draw on with imagery at ratios of less than 1:200,000. Experience in learning how to extract information from the commonly used $1: 20,000$ imagery, however, indicates that whatever our present ability may be, it will improve.

There have been a few major and dramatic developments in automatic and semiautomatic equipment for interpretation, but for the most part, these are still experimental and there is very little expertise in their use. Thus classification of land use from imagery will remain a personal task for an indefinite period of time and will only gradually become a semiautomatic process and perhaps eventually a fully automatic procedure. For the time being, the problems of information retrieval are problems of visual interpretation.

The kinds and amounts of land-use information that may be obtained from different sensors depend on the altitude or the resolution of each. There is little likelihood that any one sensor or system will produce good information at all altitudes. It would be desirable to evaluate each source of remote-sensing information and its application solely on the basis of the qualities and characteristics of the source. However, it is common practice to transfer the data to a base map, and no matter what our guidelines, it is difficult to use a base map without extracting some additional information. Topographic maps contain an abundance of information, and even road maps or a detailed city map will contribute detail beyond the capabilities of the remote-sensor image employed.

The land-use classification system described in this report has been developed on the assumption that different sensors will provide information for different levels of classification. In general, the following relations are anticipated:
Classification Level

I
Source of information

Satellite imagery, with very little supplemental information. 
Classification Level-Con. Source of Information-Con.

II $\ldots \ldots \ldots$. . .

III

IV

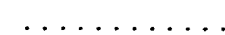
topographic maps.
High-altitude and satellite imagery combined with

Medium-altitude remote sensing $(1: 20,000)$ combined with detailed topographic maps and substantial amounts of supplemental information.

Low-altitude imagery with most of the information derived from supplemental sources.

Satellite imagery from ERTS-A and ERTS-B will generally be prepared for users at a ratio of $1: 1,000,000$. At this ratio, 1 centimeter represents 10 kilometers or 1 inch equals about 16 miles. Even if information is generated by transferring data to much larger scale maps, only a general classification, based on major differences in land cover, can be made. This would also be true for imagery at ratios up to 1:250,000, and Level I would be appropriate for these sources also.

Second-level units of classification are based on retrieval from imagery at a ratio of about $1: 100,000$. At this ratio, 1 centimeter represents 1 kilometer and 1 inch equals about 1.6 miles. Information can be transferred with reasonable accuracy to fairly detailed maps, even to the U.S. Geological Survey 1:24,000 topographic maps, and a substantial amount of supplemental input can be obtained. The greater detail will allow classification on the basis of more specific uses of land rather than only nine major types of cover, and the complexity of the inventory can be increased.

The categories proposed at Level II cannot all be interpreted with equal reliability. In parts of the United States, some may be extremely difficult to interpret from high-altitude aircraft imagery alone. Rather than mutilate the categorization or distort it and so reduce the number of useful applications, it seems preferable to suggest that additional steps be taken to obtain a satisfactory interpretation. Conventional aerial photography and sources of information other than remote sensor data may be needed for interpretation of especially difficult areas. On the basis of tests in the
Central Atlantic Regional Ecological Test Site, the Phoenix Pilot Project, and land-use mapping for the Ozark Regional Commission, we believe that the cost of using such supplementary information can be held to reasonable levels.

At Level III, which is beyond the scope of the present discussion, we would look forward to using substantial amounts of supplemental information in addition to remotely sensed information at ratios of $1: 40,000$ to $1: 15,000$. At a typical ratio of $1: 24,000,1$ inch represents 2,000 feet, and information can be transferred directly to the 1:24,000 topographic maps. Surprisingly detailed inventories may be undertaken, and by using both remotely sensed and supplemental information, most land uses except those of the very complex urban areas or the thoroughly heterogeneous mixtures can adequately located, measured, and coded.

Level IV of the projected classification would call for much more supplemental information and remotely-sensed data at a much larger scale.

\section{Development of the Classification System}

The needs of Federal agencies for a broad overview of national land-use patterns and trends and environmental values led to the formation in early 1971 of an Inter-Agency Steering Committee on Land Use Information and Classification. The work of the committee, composed of representatives from the Geological Survey of the U.S. Department of the Interior, the National Aeronautics and Space Administration, the Soil Conservation Service of the U.S. Department of Agriculture, the Association of American Geographers, and the International Geographical Union, has been supported by NASA and the Department of the Interior and has been coordinated by the U.S. Geological Survey.

One objective of the committee was the development of a national classification system that would be receptive to inputs of data from both conventional sources and remote sensors on high-altitude aircraft and satellite platforms, 
and that would at the same time form the framework into which the categories of more detailed land-use studies by regional, state, and local agencies could be fitted and aggregated upward for more generalized smaller-scale use at the national level.

Several land-use classification systems designed for or amenable to use with remote-sensing techniques served as the basis for discussion at a Conference on Land Use Information and Classification in Washington, D.C., June 28-30, 1971, attended by more than 150 representatives of Federal agencies, state and local governments, universities, institutes, and private concerns. On the basis of these discussions, the steering committee then proposed to develop and test a land-use classification system that could be used with remote sensing and minimal reliance on supplemental information at the more generalized first and second levels of categorization. The need for compatibility with the more generalized levels of land-use categorization in classification systems currently in use was clearly recognized, especially those of the Standard Land Use Coding Manual, the Inventory of Major Uses of Land and Water made every 5 years by the Economic Research Service of the U.S. Department of Agriculture, and the National Inventory of Soil and Water Conservation Needs, initiated in 1956 and carried out for the second time in 1966 by several agencies of the U.S. Departments of Agriculture and Interior.

Two land-use classification systems initially proposed by James R. Anderson for conference use were designed to place major reliance on remote sensing, although supplementary sources of information were assumed to be available for the more elaborate of the two. The classification system for the New York State Land Use and Natural Resources Inventory, developed mainly at the Center for Aerial Photographic Studies at Cornell University, had been designed for use with aerial photography at the 1:24,000 scale, and although devised specifically for New York State, it was adaptable for use elsewhere. To take advantage of the New York experience,
Ernest E. Hardy and John T. Roach were invited to collaborate in preparing the definitional framework of the proposed classification. Definitions of land-use categories used in New York have been carefully reviewed in relation to the more varied and complex definitional framework needed for the entire United States and have been modified to make them applicable to the country as a whole. Attention was given mainly to the more generalized first and second levels of categorization. Definitions for each of the categories on these two levels were subjected to selective testing and evaluation by the Geological Survey, using imagery obtained primarily from high-altitude flights as part of the research in connection with the Central Atlantic Regional Ecological Test Site, the Phoenix Pilot Project, and Land Use Mapping for the Ozark Regional Commission.

The work of Lawrence R. Pettinger of the Forestry Remote Sensing Laboratory of the School of Forestry and Conservation at the University of California at Berkeley and Charles E. Poulton of Oregon State University on "The Application of High Altitude Photography for Vegetation Resource Inventories in Southeastern Arizona" under contract with the National Aeronautics and Space Administration, which was being conducted at the same time as our development and testing program, provided valuable insights into the land use mosaic of the Southwestern United States. The hierarchical classification of barren lands and natural vegetation (rangeland) for that part of the United States is a significant contribution to the development of a land-use classification system and procedures amenable to use with remote-sensing techniques. Some of the definitional structure for barren land and rangeland suggested by Pettinger and Poulton has been adopted in this land-use classification system being proposed for general use throughout the United States.

In developing the land-use classification system, we have made an effort to provide compatibility with the classification systems currently used by the several Federal agencies making land-use inventories. However, when 
complete or nearly complete reliance is placed on remote sensing as an inventory technique, it is not possible to obtain complete compatability with the categorization of land use employed with enumeration and observation techniques. Considerable care should be exercised in comparing land-use classifications based on data obtained by remote sensing and the definitions proposed in this report with classifications based on data obtained by enumeration and observation and category definitions written for use with those techniques. The definitions given in the concluding section of this report must be studied carefully before analyzing land-use information that has been classified in accord with the proposed classification system.

As further advances in technology are made, it may be necessary to modify the classification system for use with automatic data analysis. The ERTS-A and Skylab missions and the high-altitude aircraft program of the National Aeronautics and Space Administration offer an excellent opportunity for nationwide testing of the feasibility of using this classification system to obtain land-use information on a uniform basis.

In summary, the land-use classification system being presented in this report includes only the more generalized first and second levels of classification. The definitional structure is a first approximation, capable of further refinement on the basis of more extended and varied use. We believe, however, that it meets the principal immediate objective of providing a land-use classification system for use with major research activities in the testing of remote-sensing techniques, and that it will be possible to use this proposed system with large-scale imagery as well as with other methods of collecting land-use data such as direct enumeration and observation. Attainment of the more fundamental and long-range objective of providing a standardized system of land-use classification for national and regional studies will depend on the effective revision and improvement that should result from widespread review and use of the system. Because it is impractical to circulate unpublished manuscripts widely, this manuscript is being submitted for review and testing in the form of a U.S. Geological Survey circular.

\section{Land-Use Classification System for Use With Remote Sensor Data}

\author{
Level I Level II
}

01. Urban and Built-up Land.

01. Residential.

02. Commercial and services.

03. Industrial.

04. Extractive.

05. Transportation, Communications, and Utilities.

06. Institutional.

07. Strip and Clustered Settlement.

08. Mixed.

02. Agricultural Land.

09. Open and Other.

01. Cropland and Pasture.

02. Orchards, Groves, Bush Fruits, Vineyards, and Horticultural Areas.

03. Feeding Operations.

04. Other.

03. Rangeland.

01. Grass.

02. Savannas (Palmetto Prairies)

03. Chaparral.

04. Desert Shrub.

04. Forest Land.

01. Deciduous.

02. Evergreen (Coniferous and Other).

05. Water.

03. Mixed.

01. Streams and Waterways.

02. Lakes.

03. Reservoirs.

04. Bays and Estuaries.

05. Other.

06. Nonforested Wetland.

01. Vegetated.

02. Bare.

07. Barren Land.

01. Salt Flats.

02. Beaches.

03. Sand Other Than Beaches.

04. Bare Exposed Rock.

05. Other.

08. Tundra.

01. Tundra.

09. Permanent Snow and Icefields.

01. Permanent Snow and Icefields. 


\section{DEFINITIONS}

In the definitions presented here, an attempt has been made to include sufficient detail to provide a general understanding of what is included in each category at Levels I and II. Many of the uses described in detail will not be visible on spacecraft and high-altitude imagery. However, the detail will aid in the interpretation process, and the additional information will be useful to those who have large-scale aerial photographs and other supplemental information available.

\section{Urban and Built-Up Land}

Urban and Built-up Land comprises areas of intensive use with much of the land covered by structures. Included in this category are cities, towns, villages, strip developments along highways, transportation, power, and communications facilities, and such isolated units as mills, mines, and quarries, shopping centers, and institutions.

As development progresses, small blocks of land of less intensive or nonconforming use may be isolated in the midst of built-up areas and will generally be included in the 01-category. Agricultural, forest, or water areas on the fringe of Urban and Built-up areas will not be included except where they are part of low-density urban development. The Urban and Built-up Land category takes precedence over others when the criteria for more than one category are met. Thus, residential areas that have sufficient tree cover to meet Forest Land criteria will be placed in the Residential category.

The Level II categories of Urban and Built-up Land are: Residential; Commercial and Services; Industrial; Extractive; Transportation, Communications, and Utilities; Institutions; Strip and Clustered Settlements; Mixed; and Open and Other.

\section{1-01. RESIDENTIAL}

Residential land uses range from high density, represented by the multiple-unit structures of urban cores, to low density, where houses are on lots of more than an acre, on the periphery of urban expansion. Linear residential developments along transportation routes extending outward from urban areas should be included as residential appendages to urban centers, but care must be taken to distinguish them from commercial strips in the same locality. The residential strips generally have a uniform size and spacing of structures, linear driveways, and lawn areas; the commercial strips are more likely to have buildings of different sizes and spacing, large driveways, and parking areas. Residential development along shorelines is also linear and sometimes extends back only one residential parcel from the shoreline to the first road.

Areas of sparse residential land use will be included under another category. In some places, the boundary will be clear where new housing developments abut against intensively used agricultural areas, but the boundary may be vague and difficult to discern when residential development is sporadic, or occurs in small isolated units over an extended period of time in areas of mixed or less intensive uses. A careful evaluation of density and the overall relation of the area to the total urban complex must be made.

Residential sections may also be included in other use categories where they are integral parts of the other use. Housing on military bases, at colleges and universities, living quarters for laborers near a work base, or lodging for employees of agricultural field operations or resorts are often difficult to identify and may be placed within the institutional, industrial, agricultural, or commercial categories.

\section{1-02. COMMERCIAL AND SERVICES}

Commercial areas are those used predominantly for the sale of products and services. They are often abutted by residential, agricultural, or other contrasting uses which help define them. The principal components of the Commercial-use category are urban central business districts; shopping centers, usually in 
suburban and outlying areas; commercial strip developments along major highways and access routes to cities; and resorts. The main buildings, secondary structures, and areas supporting the basic use are all included-office buildings, warehouses, driveways, sheds, parking lots, landscaped areas, and waste-disposal areas.

Commercial areas may include some noncommercial uses too small to be separated out. Central business districts often include some institutions, such as churches and schools, and commercial strip developments may include some residential units. These are not separated out unless they exceed one-third the total commercial area. Recreational areas are not segregated as such at Level II but may cause some problems in identification. Recreational facilities that form an integral part of an institution should be included in the Institutional category. A self-contained sports area, on the other hand, such as a stadium for professional events, is Commercial. There is usually a major visible difference in the form of parking facilities, arrangements for traffic flow, and the general association of buildings and facilities. Near a resort, the intensively developed recreational areas would be included in the Commercial category, but extensive golf courses and riding areas would be included in another category, the Open and Other, if in an urban setting. Public and private golf courses, ski and toboggan areas, and other recreational facilities are also classed as Open land.

\section{1-03. INDUSTRIAL}

Industrial areas include a wide array of uses from light manufacturing and industrial parks to heavy manufacturing plants. Identification of light industries-those focused on design, assembly, finishing, and packaging of products-can often be based on the type of building, parking, and shipping arrangements. Light industrial areas may be, but are not necessarily, directly in contact with urban areas; many are now found at airports or in relatively open country. Heavy industries use raw materials such as iron ore, lumber, or coal. Included are steel mills, pulp or lumber mills, electric power generating stations, oil refineries and tank farms, chemical plants and brick-making plants. Stock piles of raw materials, large power sources, and waste product disposal areas are usually visible, along with transportation facilities capable of handling heavy materials.

\section{1-04. EXTRACTIVE}

Extractive Land encompasses both surface and subsurface mining operations, such as sand and gravel pits, stone quarries, oil and gas wells, and metallic and nonmetallic mines. In size, these activities range from the unmistakable giant strip or pit mines covering vast areas to the unidentifiable gas wells less than a foot square. Surface structures and equipment may range from a minimum of a loading device and trucks to extended areas with access roads, processing facilities, stockpiles, equipment sheds, and numerous vehicles. Spoil material and slag heaps are usually found within a short trucking distance of the major mine areas and may be the key indicator of underground mining operations. Uniform identification of all these diverse extractive uses is extremely difficult from remote sensor data alone.

Industrial complexes where the extracted material is refined, packaged, or further processed are included in the Industrial category even if the plant is adjacent to the mine. Areas of future reserves are included in the appropriate present-use category, Agricultural or Forest Land, regardless of the expected future use. Unused pits or quarries that have been flooded are placed in the Water category if the water body is larger than 40 acres. Areas of tailings, abandoned pits and quarries, and strip-mined areas may remain barren for decades unless steps are taken to hasten the establishment of vegetation. Until vegetative cover is established, such parcels remain in the Extractive category.

\section{1-05. TRANSPORTATION, COMMUNICATIONS, AND UTILITIES}

Major transportation routes and areas greatly influence other land uses, and many land-use boundaries are outlined by them. The types and extent of transportation facilities in a locality 
determine the degree of access and affect both the present and potential use of the area.

Highways and railways are characterized by areas of activity connected in linear patterns. The highways include areas used for interchanges, limited access right-of-way, and service and terminal facilities. Rail facilities include stations, parking lots, roundhouses, repair and switching yards, and related areas, but overland track is not included unless six or more tracks are joined to give sufficient width for delineation at a scale of 1:250,000. Spur connections from an active line are included in the appropriate Industrial or Extractive category.

Airports, seaports, and major lakeports are isolated areas of high utilization, usually with no well defined intervening connections, although some water ports are connected by canals. Airport facilities include the runways, intervening land, terminals, service buildings, navigation aids, fuel storage, parking lots, and a limited buffer zone. The perimeter fence around airports usually makes a very sharp boundary that is visible on high-altitude imagery. Small airports, such as those on rotatable farm land, heliports, and land associated with seaplane bases are not included. Port areas include the docks, shipyards, drydocks, locks, and watercourse-control structures.

Communications and utilities areas involved in transport of water, gas, oil, electricity, and areas used for airwave communications are also included in this category. Pumping stations, electric substations, and areas used for radio, radar, or television antennas are the major types. Small facilities, or those associated with an industrial, commercial, or extractive land use, are included within the larger category with which they are associated. Long-distance gas, oil, electric, telephone, water, or other transmission facilities rarely constitute the dominant use of land over which they pass. If these uses are dominant and meet the minimum width criteria, they may be identified as transportation uses.

\section{1-06. INSTITUTIONAL}

Education, religious, health, correctional, and military facilities are the main components of this subcategory. All buildings, grounds, and parking lots that compose the facility are included within the institutional unit, but areas not specifically related to the purpose of the institution should be placed in the appropriate category. Auxiliary land uses, particularly residential, commercial and services, and other supporting land uses on a military base would be included in the Institutional subcategory, but agricultural areas not specifically associated with correctional, educational, or religious institutions are placed in the appropriate agricultural category. Small institutional units, as, for example, many churches and some secondary and elementary schools, will not meet the minimum area requirements and will be included within another category, usually Residential or Commercial. Historic forts may be confused with correctional institutions because of the similarity of buildings, but the historical sites have larger parking areas and often smaller landscaped or grass areas.

\section{1-07. STRIP AND CLUSTERED SETTLEMENT}

The Strip and Clustered Settlement category includes developments along transportation routes and the smaller cities, towns, and built-up areas where separate land uses may not be distinguishable. Residential, commercial, industrial, institutional, and occasionally other land uses may be included. Farmsteads intermixed with strip or cluster settlements will be included within the built-up land, but other agricultural land uses should be excluded.

\section{1-08. MIXED}

This category is used for a mixture of second-level urban uses in larger cities (more than 50,000 inhabitants) where no one use predominates. In any category, as much as one-third intermixture of another use is allowed without changing the basic classification, but where the intermixture is greater, where several uses, though each is less than one-third, are included, or where individual second-level units may be too small to be separated although the aggregate of such uses may be large, the Mixed category is used. 
Open land consists of golf courses, some parks, ski areas, cemeteries, and undeveloped land within an urban setting. Open land may be in very intensive use but a use that does not require structures. Other land includes the small blocks of less intensive or nonconforming uses that become isolated.

\section{Agricultural Land}

Agricultural Land may be broadly defined as land used primarily for production of farm commodities. On high-altitude imagery, the chief indications of agricultural activity will be symmetrical patterns made on the landscape by use of mechanized equipment. However, pasture and other lands where such equipment is used infrequently may not show as well-defined shapes as other areas.

Symmetrical patterns are also characteristic of Urban and Built-up Lands because of street layout and development by blocks. Distinguishing between Agricultural and Urban and Built-up Lands should ordinarily be possible on the basis of urban activity indicators and the associated concentration of population. The number of building complexes is smaller and the density of the road and highway network is much lower in Agricultural Lands than in Urban and Built-up Land. Some urban land uses, such as parks and large cemeteries, however, may be mistaken for Agricultural Land, especially when they occur on the periphery of the urban areas.

The interface of Agricultural Land with other categories of land use may sometimes be a transition zone in which there is an intermixture of land uses at first and second levels of categorization. Where farming activities are limited by wetness, the exact boundary may also be difficult to locate, and Agricultural Land may grade into swamp Forest Land, Nonforested Wetland, or Water.

The Level II categories of Agricultural Land are: Cropland and Pasture; Orchards, Groves, Vineyards, Bush Fruits, and Horticultural Areas; Feeding Operations; and Other.
The several components of Cropland and Pasture now used for agricultural statistics include: Cropland harvested; cultivated summer fallow and idle cropland; land on which crop failure occurs; cropland in soil improvement grasses and legumes; cropland used only for pasture or pasture in rotation with crops; pasture on land more or less permanently used for that purpose. From imagery alone, it is generally not possible to make a distinction between Cropland and Pasture with a high degree of accuracy and uniformity, let alone a distinction among the various components of Cropland. Moreover, some of the categories listed represent the condition of the land at the end of the growing season, and will not apply exactly to imagery taken at other times of the year. They will, however, be a guide to identification of Cropland and Pasture.

Certain factors vary throughout the United States and this variability must also be recognized; field size depends on topography, soil types, sizes of farms, kinds of crops and pastures, capital investment, labor availability and other conditions. Irrigated land in the Western States is easily recognized in contrast to Rangeland, but in the Eastern States, irrigation by use of overhead sprinklers cannot always be detected from imagery unless distinctive circular patterns are created. Drainage or water control on land used for cropland and pasture may also create a recognizable pattern that may aid in identification of the land use. In areas of quick-growing crops a field may appear to be in nonagricultural use unless the temporary nature of the inactivity is recognized.

02-02. ORCHARDS, GROVES, VINEYARDS, BUSH-FRUIT AND HORTICULTURAL AREAS

Orchards, groves, vineyards, and bush-fruit areas produce the various fruit, nut, and berry crops. Horticultural areas include nurseries, floricultural areas, and seed-and-sod areas used perennially for that purpose. Many of these areas may be included in another category, 
generally Cropland and Pasture, when identification is made by use of satellite or high-altitude imagery alone. Identification may be aided by recognition of the combination of soil qualities and climatological factors needed for these operations: water bodies in close proximity to moderate the effects of short duration temperature fluctuations; site selection for air drainage on sloping land; deep, well-drained soils on slopes moderate enough to permit use of machinery. Isolated orchards of a few acres do not constitute commercial orchards large enough to identify on high-altitude imagery, and remnants of the few acres of fruit trees on the family farm are usually not recognizable and are therefore not included.

\section{2-03. FEEDING OPERATIONS}

Feeding Operations are large, specialized, livestock-production enterprises, chiefly beef cattle feedlots and large poultry farms, but also including large hog and fur-bearing animal farms. These operations have large animal populations restricted to relatively small areas. The result is a concentration of waste material that is an environmental concern. The waste-disposal problems justify a separate subcategory for these relatively small areas. Feeding Operations have a built-up appearance, chiefly composed of buildings, much fencing, access paths, and waste-disposal areas. Some are located near an urban area to take advantage of transportation facilities and proximity to processing plants.

Feeding operations in conjunction with another farm enterprise are not included. Also excluded are shipping corrals and other temporary holding facilities. Game farms and zoos do not meet the animal-population densities to be placed in this subcategory.

\section{2-04. OTHER AGRICULTURAL LAND}

Inactive agricultural land is an important component of this subcategory. Such land has no physical indication of present agricultural use and no natural cover, such as brush, which would curtail its ready use for agriculture. Farmsteads, including holding areas for livestock, farm lanes and roads, ditches and canals, small farm ponds, and similar uses are generally quite small and often unrecognizable from high-altitude imagery so that these uses will generally be included with adjacent agricultural uses.

\section{Rangeland}

Rangeland may be defined as land where the potential natural vegetation is predominantly grasses, grasslike plants, forbs, or shrubs, where natural herbivory was an important influence in its precivilization state, and that is more suitable for management by ecological rather than agronomic principles. Some rangelands have been or may be seeded to introduced or domesticated plant species. Most of the rangelands in the United States are in the Western Range, the area to the west of an irregular north-south line that cuts through the Dakotas, Nebraska, Kansas, Oklahoma, and Texas. $R$ angelands are also found in the Southeastern States and Alaska.

The Level II categories of Rangeland are: Grass, Savannas (Palmetto Prairies), Chaparral, and Desert Shrub.

\section{3-01. GRASS}

This subcategory encompasses the tall grass (or true prairie), short grass, bunch grass or palouse grass, and desert grass regions. These grass regions generally represent a sequence of declining amounts of available moisture. Most of the tall grass region has been plowed for agriculture. The bulk of the remaining tall grass range is now in North Dakota, Nebraska, southern Kansas and Oklahoma, and the Texas Coastal Plain. Short grass rangeland occurs in a strip about 300 miles wide from the Texas Panhandle northward to the Dakotas where it widens to cover the western half of the Dakotas, the eastern three-fourths of Montana, and the eastern third of Wyoming.

\section{3-02. SAVANNAS (PALMETTO PRAIRIES)}

The Palmetto Prairies in south-central Florida, north, west, and southwest of Lake 
Okeechobee consist mainly of dense medium tall grasses with scattered palms and shrubs. Many areas are now in improved pasture.

03-03. CHAPARRAL

This category includes California chaparral, the scrub oak or shinnery, and the mountain brush types.

\section{3-04. DESERT SHRUB}

Vegetation in this zone includes the creosote bush, sagebrush, greasewood, and other desert shrubs. Bottom lands and moister flats are often characterized by dense stands of mesquite, and where alkali is high, desert saltbrush dominates wide areas.

\section{Forest Land}

Forest lands are lands that are at least 10 percent stocked by trees capable of producing timber or other wood products that exert an influence on the climate or water regime. Forest land can generally be identified rather easily from high-altitude imagery, although the boundary between it and other classes of land may be difficult to delineate precisely.

Lands from which trees have been removed to less than 10 percent stocking but which have not been developed for other use are also included. For example, lands on which there is forest rotation, involving clear-cutting and block planting, are part of Forest Land. On such lands, when trees reach marketable size, which for pulpwood in the Southeastern United States may occur in two to three decades, there will be large areas that have little or no visible forest growth. The pattern can sometimes be identified by the presence of cutting operations in the midst of a large expanse of forest. Unless there is evidence of other use, such areas of little or no forest growth should be included in the Forest Land category. Lands that meet the requirements for Forest Land and also for a higher use category should be placed in the higher category.

At Level II, Forest Land will be divided into three categories: Deciduous, Evergreen, and
Mixed. To differentiate the three, sequential imagery, or at least imagery during the period when deciduous trees are bare, will be necessary.

\section{4-01. DECIDUOUS FOREST LAND}

Deciduous Forest Land includes all forested areas in which the trees are predominantly those from which the leaves fall at the end of the growing period. In most parts of the United States, these would be the hardwoods, such as oak, maple, beech, ash, hickory, and aspen, and the "soft hardwoods" such as sweet gum, tupelo, cottonwood, and yellow poplar. Tropical hardwoods such as mahogany and ebony are not included as they are broad-leaved evergreens and hence are included in the Evergreen Forest Land category.

\section{4-02. EVERGREEN FOREST LAND}

Evergreen Forest Land includes all forested areas in which the trees are predominantly those which remain green throughout the year. Both coniferous and tropical broad-leaved evergreens are included in this category. In most areas, the coniferous evergreens predominate, but the mangrove swamps of Florida and some of the forests of Hawaii are notable exceptions. The coniferous evergreens are commonly referred to or classified as softwoods. They include such eastern species as the longleaf, slash, shortleaf, loblolly, and other southern yellow pines; spruce and balsam fir; white and red pines; jack pine; hemlock; and cypress; and such western species as Douglas-fir, ponderosa pine, redwood, Sitka spruce, Engelmann spruce, lodgepole pine, red cedar, larch, hemlock, and white pine.

\section{4-03. MIXED FOREST LAND}

Mixed Forest Land includes all forested areas where both evergreen and deciduous trees are growing and neither predominates.

\section{Water}

The Water category includes all areas within the land mass of the United States that are predominantly or persistently water covered, 
provided that, if linear, they are at least $1 / 8$ mile (660 feet or 200 meters) wide and if extended cover at least $1 / 8$ square mile or 40 acres. Water bodies smaller than these minimums are included within the land-use unit in which they are located. Sewage-treatment or water-supply facilities are a basic part of the urban pattern and should be included in the 01-Urban category even where the unit is large enough to be separately identified. Water bodies that are vegetated are placed in the 06-Wetland category, or in Forest Land if swamp forests exist.

There are five Level II categories: Streams and Waterways, Lakes, Reservoirs, Bays and Estuaries, and Other.

\section{5-01. STREAMS AND WATERWAYS}

This subcategory includes rivers, creeks, canals, and other linear bodies that meet the minimum width requirement of $1 / 8$ mile. Occasional constrictions of streams to less than $1 / 8$ mile may be included to preserve continuity. Streams flowing through deltas will be classified as water as long as width minimums are met, but where there are many distributaries and individual streams are less than $1 / 8$ mile wide, they will be included in the appropriate land use. Where the water course is interrupted by a control structure, the impounded area, if it exceeds 40 acres, will be placed in the Reservoirs subcategory.

The boundary between streams and lakes, reservoirs, or the ocean is the straight line across the mouth of the stream unless the mouth is more than 1 mile wide. In that case the rule given under 05-04 for bays and estuaries is followed.

05-02. LAKES

Lakes are bodies of water more than 40 acres in areal extent, but excluding reservoirs. Islands within lakes that are too small to delineate will be included in the water area. The delineation of a lake will be based on the areal extent of water at the time the imagery is taken.
05-03. RESERVOIRS

Reservoirs are artificial impoundments of water greater than 40 acres in areal extent, whether for irrigation, flood control, municipal water supplies, or hydroelectric power generation. Dams, levees, other water-control structures, or the excavation itself will usually be evident to aid in the identification.

\section{5-04. BAYS AND ESTUARIES}

Bays and estuaries are inlets or arms of the sea that extend into the land and as such are properly classified in this system only when they are included within the land mass of the United States. In order that this land mass area be commensurate with the area of the United States used in compiling census statistics, the convention used by the Bureau of the Census in setting the outer limits of the United States will be followed. Where bays and estuaries are between 1 and 10 nautical miles in width, the outer limit of the United States will be the straight line connecting the headlands except where the indentation of the embayment is so shallow that the water area would be less than the area of a semicircle drawn with this straight line as the diameter. In that event the coastline itself would form the outer limit of the United States. Embayments less than one nautical mile in width are classed as 05--01 Streams and Waterways. Embayments or portions of embayments more than 10 nautical miles wide are not considered as included within the land mass.

05-05. OTHER

Other water areas include large farm ponds that may not be identifiable as reservoirs, other water features not mentioned in the preceding categories, or combinations of water features that cannot be clearly defined.

\section{Nonforested Wetland}

Nonforested Wetlands consist of seasonally flooded basins and flats, meadows, marshes, and 
bogs. Wetlands are usually relatively level areas. Uniform identification is difficult because the wetland areas change as the result of such factors as long-term drought, high rainfall, seasonal fluctuations in precipitation, and diurnal tides. The observations must be correlated with tide and weather information to obtain consistent results.

Open saline- and fresh-water areas, sounds, and bays are included under 05-Water. Wetland areas with a 10 percent forest crown cover, or where recent clear cutting has occurred, are placed in 04-Forest Land.

Nonforested Wetland may be either Vegetated or Bare.

\section{6-01. VEGETATED NONFORESTED WETLAND}

Vegetated Nonforested Wetland includes areas where the forest crown cover is less than 10 percent or the vegetation is nonwoody. Cattails, tules, and grasses such as Indian rice grass and saw grass occur in fresh-water marshes, and salt-tolerant grasses such as Spartina occur in the salt marshes.

\section{6-02. BARE NONFORESTED WETLAND}

Tidal flats are the main component.

\section{Barren Land}

Barren land is land of limited ability to support life and little or no vegetation. In general, it appears to be an area of oily soil, sand, and rocks. Vegetation, if present, is more widely spaced and scrubby than that in the Desert Shrub subcategory of Rangeland except when unusual conditions, such as a heavy rainfall, occasionally result in growth of a short-lived more impressive plant cover.

Land may be temporarily barren owing to man's activities, but such land is usually included in another land-use category. Agricultural land may be temporarily without vegetation because of tillage practices. Sites for urban development may be stripped of cover before construction begins. Areas of extractive and industrial land have waste and tailings dumps, and exhausted sources of material supply are often evident.

Level II categories of Barren Land are: Salt Flats, Beaches, Sand Other Than Beaches, Bare Exposed Rock, and Other.

07-01. SALT FLATS

Salt flats are the flat-floored bottoms of interior desert basins. For a short time after a cloudburst, they may be covered by a sheet of water, or playa lake. On vertical air photographs they appear as white scars in the desert because the soil, flatness, and color cause a diffused reflectancy much higher than the albedo of other desert features.

\section{7-02. BEACHES}

Beaches are the smooth sloping accumulations of $\mathrm{s}$ and and gravel along shorelines. The surface is stable inland, but the shoreward part is subject to erosion by wind and water, and material is deposited in protected areas. The Beach category is not used if there is vegetative cover or another land use.

\section{7-03. SAND AND OTHER THAN BEACHES}

Sand Other Than Beaches is composed primarily of dunes, accumulations of sand of aeolian origin. Dunes are most commonly found in deserts although they also occur on shore and strand lines, coastal plains, river flood plains, deltas, and in periglacial environments. They are of various shapes, the crescentic being the most elementary, and range in size from diameters of a few to several thousand meters and in height from one to several hundred meters. Isolated crescent-shaped dunes migrate freely, but longitudinal dunes tend to remain nearly fixed in position.

\section{7-04. BARE EXPOSED ROCK}

The Bare Exposed Rock category includes areas of bedrock exposure, desert pavement, 
scarps, talus, slides, volcanic material, and other accumulations of rock without vegetative cover.

\section{7-05. OTHER}

This subcategory is used for a mixture of Barren Land features or when a Barren Land subcategory cannot be positively identified.

\section{Tundra}

Tundras are cold treeless lands, primarily in Alaska, with a vegetative cover of moss and lichen, grasses, and shrubs. The tundra zone can be divided into three subzones on the basis of vegetative cover: an arctic subzone characterized by an interrupted cover of sparse moss and lichen sedges: a typical tundra subzone characterized by various types of moss and lichen sedges and rare shrubs in river valleys; and a shrub tundra subzone, characterized by birch and willow shrubs together with mosses, sedges, and grasses. Mountain tundra, along the mountain tops, extends well to the south and is enriched by alpine flora.

The interfaces of Tundra to Permanent Snow and Icefields and to Water are fairly easily determined if the imagery is taken in late summer. Between Forest Land with a light crown cover and Tundra, the boundary tends to be transitional over a wide area and is also uneven, as changes in growing conditions bring about protuberances of brushland into Tundra areas. Distinguishing between Tundra and Nonforested Wetland is difficult where there is a hummocky landscape with intervening areas of standing water. Flooded portions may vary in size owing to seasonal changes in depth of frost, amount of precipitation, and evapotranspiration potential. The ratio of flooded land to vegetation is the basis for decision. The Barren Land-Tundra interface occurs where one or more of the vegetative growing factors are deficient. The boundary will be difficult to establish.

\section{Permanent Snow and Icefields}

Permanent Snow and Icefields are those that survive summer ablation. Snow, firn, icepacks, icecaps, and glaciers are included and the underlying mass may be either land or water. An average frontal position over a period of a few years would be the most desirable border, but an expedient delineation can be made through observations at the time of maximum retreat, probably during August in the northern hemisphere. The abutting land would most probably be classed as Water, Barren Land, Tundra, or Nonforested Wetland.

\section{Selected References}

Anderson, James R., 1971, Land use classification schemes used in selected recent geographic applications of remote sensing: Photogramm. Eng., v. 37 , no. 4 , p. $379-387$.

Avery, T. Eugene, 1968, Interpretation of aerial photographs [2d ed.]: Minneapolis, Burgess Publishing Co., 324 p.

Barlowe, Raleigh, 1972, Land resource economics [2d ed.]: Englewood Cliffs, N.J., Prentice Hall Inc., $585 \mathrm{p}$.

Burley, Terence M., 1961, Land use or land utilization?: Prof. Geographer, v. 13, no. 6, p. 18-20.

Canada Department of Forestry, 1966, The Canada land inventory: Ottawa, Canada Dept. Forestry, $61 \mathrm{p}$.

Clawson, Marion, and Stewart, Charles L., 1965, Land use information. A critical survey of U.S. statistics including possibilities for greater uniformity: Baltimore, Md., The Johns Hopkins Press for Resources for the Future Inc., $402 \mathrm{p}$.

Cline, Marlin G., 1949, Basic principles of soil classification: Soil Sci., v. 67, p. 81-91.

Hardy, Ernest E., Belcher, Donald J., and Phillips, Elmer S., 1971, Land use classification with simulated satellite photography: U.S. Dept. Agriculture Econ. Research Service Agr. Inf. Bull. $352 \mathrm{p}$.

Marschner, F. J., 1959, Land use and its patterns in the United States: U.S. Dept. Agriculture Agr. Research Service Agr. Handb. 153, 277 p.

National Academy of Sciences, 1970, Remote sensing with special reference to agriculture and forestry: Washington, D.C., Natl. Acad. Sci.

New York State Office of Planning Coordination, 1969, Land use and natural resources inventory of New York State: Albany, New York State Office Planning Coordination, $67 \mathrm{p}$.

Society of American Foresters, 1967, Forest cover types of North America: Washington, D.C., Soc. American Foresters.

Stoddart, Laurence A., and Smith, Arthur D., 1955, Range management [2d ed.]: New York, McGraw Hill Book Co., 433 p.

U.S. Congress, 1936, The Western Range: U.S. 74th Cong., 2d sess., Senate Doc. 199. 
U.S. Arctic, Desert Tropic Information Center, Research Studies Institute, 1955, Glossary of arctic and subarctic terms: Maxwell Air Force Base, Alabama, ADTIC Pub. A-105.

U.S. Department of Agriculture Conservation Needs Inventory Committee, 1966, National handbook for updating the conservation needs inventory: Washington, D.C., U.S. Dept. Agriculture Conserv. Needs Inventory Comm., 75 p.
U.S. Department of Agriculture Soil Conservation Service, 1962, Classifying rangeland for conservation and planning: U.S. Dept. Agr. Handb. 235.

U.S. Urban Renewal Administration, Housing and Home Finance Agency, and Bureau of Public Roads, 1965, Standard land use coding manual, a standard system for identifying and coding land use activities: Washington, D.C., U.S. Govt. Printing Office, 111 p. 